\title{
ANALISIS MOTIF KONSUMEN DALAM KEPUTUSAN PEMBELIAN DAN PEMAKAIAN BUMBU INSTANT MASAKAN
}

\author{
*Muhamad Al Faruq Abdullah ${ }^{1}$ \\ ${ }^{1}$ Fakultas Bisnis dan Ilmu Sosial, Program Studi Manajemen, Universitas Dian Nusantara, Jakarta, Indonesia
}

*Email Korespondensi:

alfaruq1602@gmail.com

\section{ARTIKEL INFORMASI}

Diterima:

3 March 2021

Direvisi:

15 April 2021

Dipublikasi:

16 Mei 2021

\begin{abstract}
ABSTRAK
Penelitian ini bertujuan untuk membahas dan menganalisa pembelian rempah-rempah bumbu racik Indofood di Tanggerang. Tujuan dari penelitian ini adalah untuk menentukan keputusan pelanggan untuk melakukan pembelian dan sebagai bahan pertimbangan bagi individu atau organisasi dalam mengambil kebijakan atau strategi pemasaran atau penjualan dengan mempertimbangkan keputusan pembelian di pasar. Penentuan variabel independen untuk penelitian didasarkan pada hasil survei pendahuluan melalui formulir Google untuk pelanggan yang berada di area faktor utama dalam keputusan pembelian adalah penilaian kualitas dan harga. Populasinya adalah pelanggan ras rempah Indofood di daerah Tangerang, dengan sampel sekitar 160 responden. Penelitian ini menggunakan teknik analisis data SEM dan pengolahan data menggunakan program Partial Least Square (Smart-PLS) versi 3.0. PLS (Partial Least Square).Dari hasil penelitian menunjukan bahwa kualitas produk berpengaruh terhadap keputusan pembelian dan persepsi harga berpengaruh terhadap keputusan pembelian bumbu racik instan Indofood.
\end{abstract}

Kata Kunci: Kualitas Produk,Persepsi Harga, Keputusan Pembelian

\section{PENDAHULUAN}

Pangan merupakan kebutuhan manusia yang sangat mendasar karena mempengaruhi kelangsungan hidup dan kelangsungan hidup manusia, baik dari segi kualitas maupun kuantitas. Upaya pemenuhan kebutuhan pangan di negara berkembang dapat dilakukan secara tradisional atau dengan memperluas lahan pertanian. Ketersediaan pangan yang cukup, aman, bermutu dan bergizi merupakan syarat utama yang harus dipenuhi dalam upaya mewujudkan sumber daya manusia yang berkualitas (Indriani Y, 2015). Makanan yang dimakan pada dasarnya tidak hanya untuk mengenyangkan saja, tetapi harus bergizi dan mampu menggugah selera serta menarik minat mereka yang mengkonsumsi makanan tersebut. Untuk menghasilkan makanan yang dapat memberikan aroma, warna dan rasa yang lebih sedap diperlukan berbagai macam bumbu dalam pengolahannya.

Di Indonesia terdapat beberapa produsen jamu instan, salah satunya adalah PT. Indofood Sukses Makmur Tbk yang didirikan pada tanggal 14 Agustus 1990. Awalnya PT. Indofood Sukses Makmur Tbk adalah perusahaan yang bergerak di bidang produksi mie instan. Kemudian berkembang pesat dan menjadi perusahaan yang berkomitmen menjadi perusahaan Total Food Solution. Munculnya berbagai macam produsen bumbu instan mendorong PT. Indofood Sukses Makmur Tbk mempersembahkan Indofood Racik 
Spices untuk dapat terus dipertahankan eksistensinya. Karena persaingan yang semakin ketat antar produsen bumbu instan, Racik Bumbu Indofood selalu menciptakan inovasi baru agar konsumen tidak merasa bosan dengan produknya. Selain itu, Indofood Racik Bumbu menyediakan produk berkualitas yang sesuai dengan kebutuhan dan harapan konsumen yang berbeda. Bumbu racik Indofood juga terjangkau dibandingkan kompetitor bumbu instan di pasaran, seperti Sajiku, Sasa, Royko dan MamaSuka.

Keputusan pembelian merupakan tahapan dimana konsumen mempertimbangkan beberapa faktor dan alasan yang memperkuat konsumen untuk memutuskan pembelian suatu produk atau jasa tertentu (Chifman \& Kanuk, 2013). Menurut Kotler \& Keller (2013), menyatakan bahwa keputusan pembelian adalah konsumen yang membentuk niat untuk membeli merek yang paling disukai. Sedangkan menurut Chiffman \& Kanuk (2013), keputusan pembelian adalah proses pemilihan dua atau lebih alternatif pilihan yang menghasilkan keputusan untuk membeli atau tidak. Menurut Kotler \& Armstrong (2013), faktor-faktor yang dapat mempengaruhi pembelian konsumen keputusan tentang suatu produk, termasuk kualitas produk, harga, promosi dan distribusi, atau yang dikenal dengan bauran pemasaran. Kualitas produk adalah kemampuan produk untuk mendemonstrasikan berbagai fungsi antara lain daya tahan, keandalan, akurasi, dan kemudahan penggunaan Kotler \& Armstrong (2013). Kualitas memiliki arti yang sangat penting dalam keputusan pembelian konsumen.

Hal ini diperkuat dengan penelitian sebelumnya yang dilakukan oleh Suci Mardela (2017) yang menyatakan bahwa kualitas produk berpengaruh positif dan signifikan terhadap keputusan pembelian yang artinya peningkatan kualitas produk meningkatkan keputusan pembelian. Hal tersebut membuat peneliti tertarik untuk mengangkat variabel kualitas produk dalam penelitiannya, untuk mendapatkan produk dengan kualitas yang baik maka konsumen harus mengeluarkan biaya atau yang disebut dengan harga. Menurut Kotler \& Armstrong (2013), harga adalah jumlah uang yang dibebankan untuk suatu produk atau layanan atau jumlah nilai yang dipertukarkan oleh konsumen untuk keuntungan memiliki atau menggunakan produk atau layanan tersebut. Berdasarkan hasil penelitian sebelumnya, berikut dijelaskan tentang kesimpulan beberapa peneliti, diantaranya sebagai berikut: Iful Anwar dan Budhi Satrio (2015), menyatakan bahwa kualitas produk berpengaruh positif dan signifikan terhadap keputusan pembelian. Doni Hariadi dan Soebari Martoatmojo (2012), menyatakan bahwa harga berpengaruh positif dan signifikan terhadap keputusan pembelian.

\section{KAJIAN PUSTAKA}

\section{Kualitas produk}

Menurut Kotler dan Armstrong (2012: 283), kemampuan suatu produk untuk mendemonstrasikan fungsinya, hal ini meliputi keseluruhan daya tahan, keandalan, keakuratan, kemudahan pengoperasian, dan perbaikan produk, serta atribut produk lainnya. Perusahaan perlu terus meningkatkan kualitas produk atau jasanya karena peningkatan kualitas produk dapat membuat konsumen merasa puas dengan produk atau jasa yang dibelinya, dan akan mempengaruhi konsumen untuk melakukan pembelian berulang.

Kualitas suatu produk merupakan kemampuan yang dapat dinilai dari suatu produk dalam menjalankan fungsinya yang merupakan gabungan antara durability, reliability, permanentence, kemudahan perawatan dan atribut lain dari suatu produk. Dari segi kualitas pemasar harus diukur dari segi penglihatan dan respon pembeli terhadap kualitas itu sendiri. Dalam hal ini selera pribadi sangat berpengaruh. Oleh karena itu secara umum dalam mengatur kualitas produk harus sesuai dengan kegunaan yang diharapkan.

\section{Persepsi Harga}

Menurut Stanton (1994) harga adalah jumlah nilai yang dipertukarkan konsumen dengan keuntungan memiliki atau menggunakan suatu produk atau jasa yang nilainya ditentukan oleh pembeli atau penjual melalui proses tawar menawar atau ditetapkan oleh penjual dengan harga yang sama. kepada pembeli. Peter dan Olson (2000) berpendapat bahwa persepsi harga berkaitan dengan bagaimana informasi harga dipahami sepenuhnya oleh konsumen dan memberikan makna yang dalam kepada mereka, ketika mengevaluasi dan meneliti harga suatu produk sangat dipengaruhi oleh perilaku konsumen itu sendiri. Harga suatu produk bisa dikatakan mahal, murah atau biasa saja tiap individu tidak sama karena tergantung latar belakang masing-masing individu oleh lingkungan hidup dan kondisi individu. 


\section{Keputusan Pembelian}

Menurut Kotler (2008) keputusan pembelian merupakan pilihan akhir yang diputuskan oleh konsumen dalam memenuhi keinginan dan kebutuhan pada dasarnya konsumen melakukan proses pengambilan keputusan pembelian yang sama tetapi semua proses tersebut tidak semuanya dijalankan oleh konsumen itu sendiri. Menurut Lamb (2008) keputusan membeli merupakan salah satu komponen utama dari perilaku konsumen, dengan tahapan demi tahapan yang digunakan konsumen saat membeli barang dan jasa. Menurut Schiffman Kanuk (2009) keputusan pembelian adalah pemilihan dua atau lebih alternatif pilihan keputusan pembelian, artinya seseorang dapat mengambil keputusan, harus ada beberapa alternatif pilihan, keputusan membeli dapat mengarah pada bagaimana proses dalam pengambilan keputusan tersebut. dilakukan, oleh perilaku konsumen.

\section{Persepsi Harga terhadap Keputusan Pembelian}

Penelitian yang dilakukan oleh Permana (2018) menyatakan bahwa harga memiliki peran penting dalam keputusan pembelian tetapi tidak hanya itu kualitas layanan, promosi dan citra merek juga dapat mempengaruhi keputusan pembelian konsumen, demikian pula Kuo dan Nakata (2016) yang melakukan penelitian. di Amerika Serikat mengenai persepsi harga yang mempengaruhi Hasil penelitian menunjukkan bahwa harga dan promosi berpengaruh terhadap keputusan pembelian, harga pada saat promosi mengurangi pengaruh negatif dari peringkat rendah.

H1: Persepsi Harga berpengaruh positif dan signifikan terhadap keputusan pembelian

\section{Kualitas Produk terhadap keputusan pembelian}

Kualitas produk mencerminkan kemampuan produk untuk menjalankan tugasnya yang meliputi daya tahan, keandalan atau kemajuan, kekuatan, kemudahan pengemasan dan perbaikan produk serta fitur lainnya. Kualitas baik atau buruk dinilai oleh konsumen berdasarkan persepsi mereka. Suatu produk dikatakan berkualitas jika memenuhi kebutuhan dan keinginan konsumen. Kualitas ditentukan oleh pelanggan, dan pengalaman mereka terhadap produk atau layanan. Hasil penelitian ini didukung oleh penelitian sebelumnya yang dilakukan oleh Suci Mardela (2017) yang mengungkapkan bahwa kualitas produk berpengaruh terhadap keputusan pembelian.

H2: Kualitas Produk berpengaruh positif dan signifikan terhadap keputusan pembelian

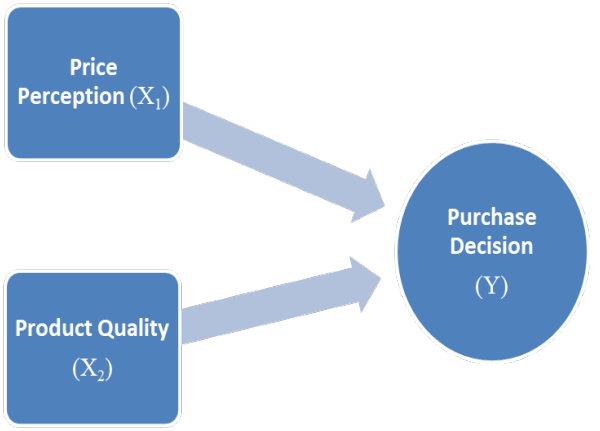

Gambar 1. Kerangka Berpikir

\section{METODE}

Penelitian penelitian ini menggunakan data kualitatif dan kuantitatif, primer dan sekunder yang dikumpulkan dari lokasi penelitian di Jakarta, Bogor, Tangerang dan Bekasi yang merupakan stratup domisili dengan jumlah dominan dari periode 2016 dan 2017. Pengumpulan data dilakukan dengan menggunakan kuesioner oleh Google Form. Pengumpulan data dilakukan dengan membaca literatur, buku-buku tentang teori masalah yang akan diteliti dan menggunakan media internet sebagai media pendukung, metode analisis untuk menguji hipotesis penelitian menggunakan Variance Based SEM dan menggunakan Partial Least Square (PLS) versi 3.0 program perangkat lunak. 


\section{HASIL DAN PEMBAHASAN}

\section{Model pengukuran}

Validitas Konvergen

Validitas konvergen yang merupakan tingkat kesesuaian beberapa item yang digunakan untuk mengukur konsep yang sama, diuji. Menurut Hair et al. (2010), faktor pembebanan, reliabilitas komposit dan rata-rata varians yang diekstraksi adalah indikator yang digunakan untuk menilai validitas konvergen.

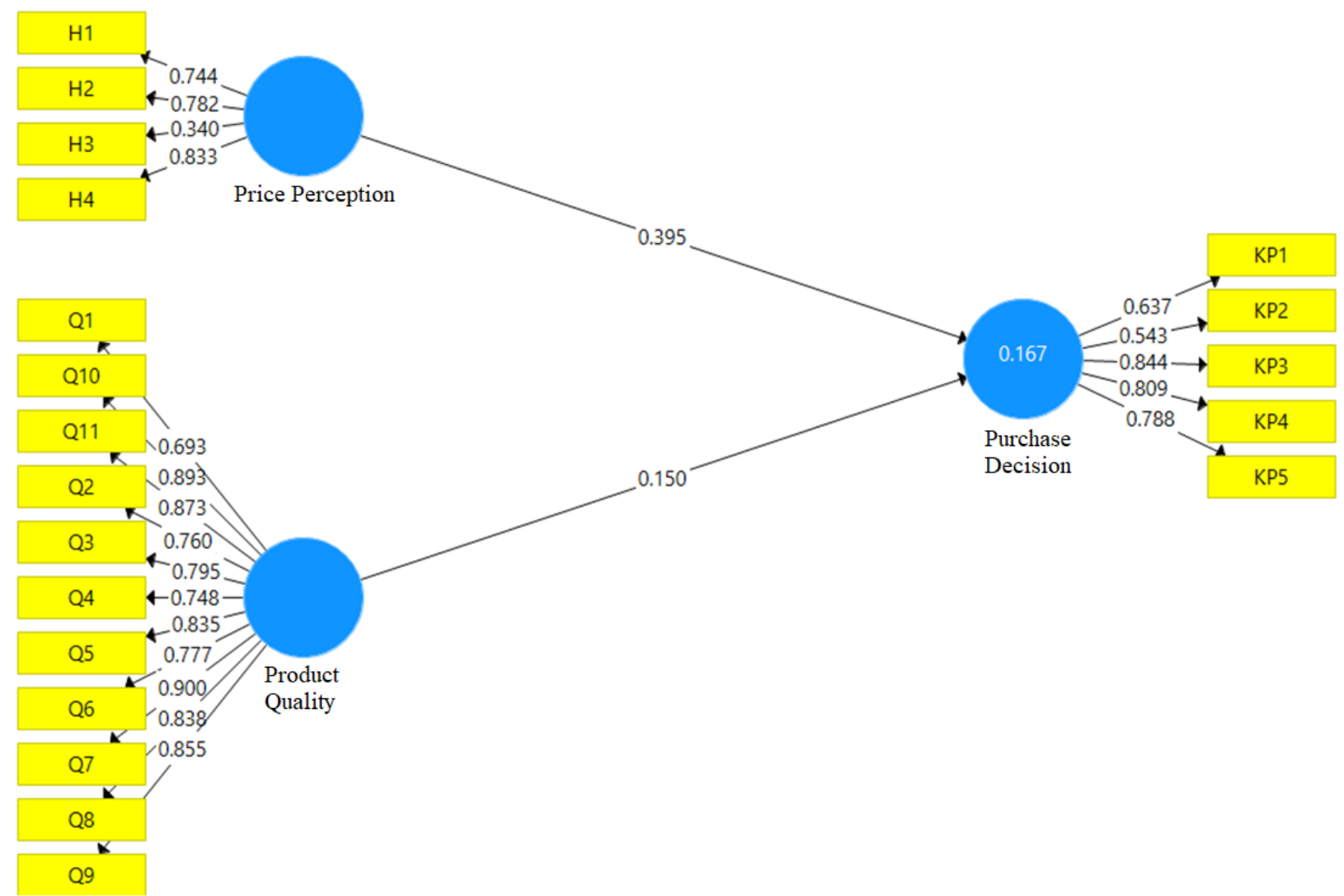

\section{Gambar 2. Model PLS}

Pemuatan untuk semua item melebihi nilai yang direkomendasikan o.6 (Chin et al. 1997). Nilai Composite Reliability (CR) (lihat tabel 1), yang menggambarkan sejauh mana indikator konstruk menunjukkan konstruk laten, berkisar antara 0,904 hingga 0,924, yang melebihi nilai yang direkomendasikan sebesar 0,7 (Hair et al. 2010). Average Variance Extracted (AVE), yang mencerminkan jumlah keseluruhan varians dalam indikator yang dihitung oleh konstruk laten, berada dalam kisaran 0,577 hingga 0,710, yang melebihi nilai yang direkomendasikan sebesar 0,5 (Hair et al. 2010). Tabel 2 menggambarkan hasil Validitas Konvergen.

\section{Validitas Diskriminan}

Diskriminan Validitas adalah sejauh mana ukuran tidak mencerminkan variabel lain dan itu ditunjukkan oleh korelasi yang rendah antara ukuran kepentingan dan ukuran konstruk lain (Chung \& Lee, 2010).

Table 1 Factor Loadings and Reliability

\begin{tabular}{lccc}
\hline & Product Quality & Purchase Decision & Price Perception \\
\hline DP1 & 0.855 & 0.799 & 0.733 \\
\hline DP2 & 0.93 & 0.821 & 0.774 \\
\hline DP3 & 0.925 & 0.774 & 0.733 \\
\hline DP4 & 0.859 & 0.79 & 0.652 \\
\hline KP3 & 0.891 & 0.911 & 0.798 \\
\hline KP4 & 0.8 & 0.913 & 0.722 \\
\hline
\end{tabular}




\begin{tabular}{llll}
\hline KP5 & 0.709 & 0.867 & 0.648 \\
\hline KP6 & 0.805 & 0.918 & 0.751 \\
\hline PH1 & 0.733 & 0.723 & 0.897 \\
\hline PH2 & 0.761 & 0.783 & 0.951 \\
\hline PH3 & 0.716 & 0.684 & 0.853 \\
\hline PH4 & 0.717 & 0.739 & 0.905 \\
\hline
\end{tabular}

Table 2 Discriminant Validity Of Construct Fornell-Lacker Criterion

\begin{tabular}{llll}
\hline & Product Quality & Purchase Decision & Price Perception \\
\hline $\begin{array}{l}\text { Product } \\
\text { Differentiation }\end{array}$ & 0.893 & & \\
\hline $\begin{array}{l}\text { Purchase } \\
\text { Decision }\end{array}$ & 0.892 & 0.902 & \\
\hline $\begin{array}{l}\text { Price } \\
\text { Perception }\end{array}$ & 0.811 & 0.812 & 0.902 \\
\hline
\end{tabular}

Note: Diagonal elements are the square root of the AVE of the reflective scales while the off diagonals are the squared correlations between constructs

Validitas diskriminan dapat diperiksa dengan membandingkan korelasi kuadrat antara konstruk dan varian yang diekstraksi untuk konstruk (Fornell \& Lacker, 1981). Seperti yang ditunjukkan pada Tabel 2, korelasi kuadrat untuk setiap konstruk lebih kecil dari akar kuadrat dari varian rata-rata yang diekstraksi oleh indikator yang mengukur konstruk tersebut, yang menunjukkan validitas diskriminan yang memadai. Dengan demikian, model pengukuran menunjukkan validitas konvergen dan diskriminan yang memadai.

\section{Model struktural}

Tabel 3 menunjukkan hasil model struktural dari keluaran PLS. Kesadaran, Persepsi Harga dan Komunikasi Pemasaran berhubungan positif dengan Niat untuk menggunakan, menjelaskan 55,8\% dari varians, sehingga mendukung $\mathrm{H} 1, \mathrm{H} 2$, dan $\mathrm{H} 3$ dari penelitian ini.

Table 3 Summary of the structural model

\begin{tabular}{llcc}
\hline Path & Hypothesis & T Statistics & Results \\
\hline Product Quality ->PD & H1 & 6.823 & Support \\
Price Perception ->PD & H3 & 2.622 & Support \\
\hline
\end{tabular}

\section{KESIMPLAN DAN SARAN}

Harga memiliki hubungan positif dan berpengaruh signifikan terhadap keputusan pembelian produk Indofood Bumbu Racik. Artinya, harga merupakan faktor terpenting yang mempengaruhi keputusan pembelian produk sejenis. Hal ini terjadi karena pembeli selalu mencari harga yang serendah mungkin untuk mendapatkan produk tersebut. Kualitas produk memiliki hubungan yang positif dan tidak berpengaruh signifikan terhadap keputusan produk Bumbu Racik Indofood. Artinya kualitas produk menjadi faktor yang tidak terlalu penting dalam mempengaruhi keputusan pembelian produk seperti Indofood Rempah Racik. Kualitas produk berupa ciri, ciri, performa, kesesuaian, daya tahan, keandalan produk pada saat berbelanja produk Indofood's Bumbu Racik kurang memperhatikan konsumen dalam memenuhi kepuasan.

Dengan nilai R-square $(\mathrm{R} 2)=0,168$ menunjukkan bahwa kemampuan variabel independen (harga dan kualitas produk) dalam menjelaskan varians variabel dependen (keputusan pembelian) sebesar 16,8\%. Sedangkan sisanya dijelaskan oleh faktor-faktor lain di luar model. Pada indeks variabel persepsi harga tertinggi terdapat pernyataan "Harga sesuai / sebanding dengan keuntungan yang diperoleh" yang artinya informasi harga dipahami sepenuhnya oleh pembeli dan konsumen sehingga memberi makna yang baik dalam hal manfaat yang diperoleh mereka.

Oleh karena itu, saran yang dapat menjadi pertimbangan bagi pemilik, pengusaha dan penjual produk sejenis Bumbu Racik Indofood adalah memberikan informasi yang jelas dan lengkap dalam bentuk foto dan 
deskripsi produk. Informasi dapat berupa informasi bonus, jaminan, spesifikasi, fungsi, keunggulan, ukuran, warna, manfaat dan promo. Selanjutnya jika memungkinkan buatlah video tentang produk karena video tersebut akan lebih memudahkan dalam menyampaikan informasi dan mengedukasi calon pembeli. Pada indeks variabel kualitas produk tertinggi terdapat pada dimensi reliabilitas dengan pernyataan indikator "Pelapak Sesuai Harapan" yang artinya keandalan (reliability), produk yang dijual dianggap sesuai dengan yang dijanjikan atau sesuai dengan pesanan yang diiklankan, paling diharapkan di produk berkualitas.

Oleh karena itu, saran yang dapat dijadikan bahan pertimbangan untuk produk sejenis Bumbu Racik Indofood adalah agar barang / produk yang dikirim sesuai dan berfungsi dengan baik. Jika memungkinkan buatlah tim khusus untuk mengecek ulang atau melakukan uji kualitas penuh sebelum pesanan dikemas dan dikirim ke penjual atau distributor.

\section{REFERENCES}

Adrian,Payne.(2014).Pemasaran Jasa; The Essence of Service Marketing. Yogyakarta, Andi. Anderson, Juaneda, and Sastre. (2008). "Influence of pro-all-inclusive Travel".Tourism Review, VOL. 64(2), pp. 418

Akbarini, Yoga. (2017). Pengaruh Kelompok Referensi. Diferensiasi Produk, dan Harga Terhadap Keputusan Pembelian Produk Perawatan (Studi Pada Konsumen Larissa Aesthetic Center Cabang Ponorogo). Jurnal Ilmu Manajemen Vol 15(3)pp 33-44, Universitas Negeri Surabaya.

Currey dan Wesley. (2007). "Going where the Joneses go: understanding how others influence travel decisionmaking". International Journal of Culture, Tourism and Hospitality Research. Vol. 2(1), pp.12-24

Defriansyah, Daud, dan Nailis. (2016). Pengaruh Citra Merek, Harga, dan Kualitas Produk Terhadap Keputusan Pembelian Smartphone Samsung (Studi Kasus Mahasiswa Universitas Sriwijaya Indralaya). Jurnal Ilmiah Manajemen Bisnis dan Terapan. Vol 8(1)pp 101-114. Universitas Sriwijaya.

Ghufran, Abdurrahman. (2014). Analisis Pengaruh Harga, Promosi, Kualitas Pelayanan, dan Citra Merek Terhadap Keputusan Pembelian konsumen. Universitas Diponegoro

Klamler dan Pferschy. (2007). "The traveling group problem". Soc Choice Welfare. 29:429-452

Methaq Ahmed Sallam. (2014). "The Effects of Brand Image and Brand Identification on Brand Love and Purchase Decision Making: The Role of WOM". International Business Research; Vol. 7, No. 10;2014.

Kotler, Philip. (2008). Manajemen Pemasaran, Edisi 12 Jilid 2. Jakarta: Indeks

Kottler, Philip dan Keller. (2009). Manajemen Pemasaran. Jilid 1. Edisi ke 13 Jakarta: Erlangga.

Notari dan Ferencz. (2014). "Consumer Price Sensitivity in Decision Making on The Purchase of Traditional Hungarian Horticultural Products. International Journal of Engineering. Vol. 19(2), pp. 4-18. Tome XII.

Kuo dan Nakata. (2016). "Price promotions and products with low consumer ratings". Journal of Consumer Marketing. Vol 33 (7) • 517-527

Nugroho, Rostiani, dan Gitosudarmo. (2014). "The Impacts Of Country-Of- Origin, Product Involvement, And Product Familiarity On Product Evaluation”. Journal of Indonesian Economy and Business. Vol 29 (2), 2014, $165-182$.

Peter, J. Paul dan Jerry C. Olson. (2000). Perilaku Konsumen dan Strategi Pemasaran. Jilid 1. Edisi Empat. Alih Bahasa: Damos Sihombing, MBA dan Peter Rem Yossi Pasla, MBA. Jakarta: Erlangga.

Schiffman, Leon, G dan Kanuk, Leslie, L. (2007). Perilaku Konsumen. Edisi Kedua. Jakarta: PT Indeks Gramedia.

Schiffman, L, G. dan, L. L. Kanuk. (2009). Persepsi kualitas, Consumer Behavior. New Jersey: Perason Prestice Hall.

Schiffman, Leon, G dan Kanuk, Leslie. (2010). Perilaku Konsumen. Jakarta: PT. INDEK.

Sifa, Ravena. (2016). Analisis Pengaruh Inovasi Produk, Persepsi Harga, Lokasi, dan Word of Mouth Terhadap Proses Keputusan Pembelian Venus Bakery (Studi Kasus Pada Konsumen Venus Bakery Jalan Pajajaran Bogor Timur). Jurnal Ekonomi dan Bisnis. Universitas Islam Negeri Syarif Hidayatullah Jakarta.

Silva dan Correia. (2007). "Facilitators and constraints in leisure travel participation: the case of the southeast of Portugal". International Journal of Culture, Tourism and Hospitality Research Vol. 2 No. 1, 2008 pp. $25-43$.

Sinaga, Supriono. (2010). "Potensi dan Pengembangan Objek Wisata di Kabupaten Tapanuli Tengah". Kertas Karya. Program DIII Pariwisata. Universitas Sumatera Utara.

Spillane, James J. (1989) Pariwisata Indonesia; Siasat Ekonomi Dan Kebudayaan, Yogyakarta: Kanisius. 
Stanton, William, J (1994). Fundamental of Marketing. Thenth ed. Mc, Graw Hill Inc; Singapore

Tupen, Imelda. (2015) Pengaruh Diferensiasi Produk, Merek, Harga, dan Promosi Terhadap Keputusan Pembelian Konsumen Pada Produk Pasta Gigi Pepsodent di Surabaya.

William J. Stanton. (1998). Prinsip Pemasaran, Jilid 1, Edisi 7, Erlangga, Jakarta.

Zahra, Dwi Murry. (2016). Pengaruh Gaya Hidup Sehat, Harga, dan Kelompok Referensi Terhadap Keputusan Pembelian Susu Anlene di Kebumen. Jurnal Ilmu Managemen,Universitas Muhammadiyah Purworejo.

Zalukhu, Sukawati \& Meyers, Koen. (2009). Panduan Dasar Pelaksanaan Ekowisata. Jakarta: Unesco Office.

Zhu dan Chang. (2014). "Effects of free gifts with purchase on online purchase satisfaction". Internet $\begin{array}{lllllll}\text { Research. } & \text { Vol. } & 25 & \text { No. 5, } 2015 & \text { pp. } & \text { 690-706 } & \text { Website: }\end{array}$ www.indonesia.irib.irwww.nationalgeographic.co.idwww.kemenpaar.go.id 